\title{
Una mirada teológica al poder. Aportes al discernimiento antropológico trascendental de la corrupción
}

\author{
JORGE AROS VEGA* \\ Pontificia Universidad Católica de Valparaíso (Chile) \\ jorge.aros@pucv.cl
}

\section{Resumen}

En el siguiente artículo se pretende hacer una lectura teológica del poder siguiendo a Karl Rahner en su concepción del mismo como don, tarea y posibilidad. El poder es don divino para el ser humano el cual participa del poder de Dios, sin embargo, cuando lo ejerce puede corromperse y pierde la finalidad para lo que es entregado. De este modo, el mal ejercicio del poder tiene repercusiones tanto para la persona como para la sociedad, graves consecuencias, por eso es necesario asumir la responsabilidad de cada acción. En este sentido, el ejercicio del poder es una tarea esencial para la vida en sociedad y, a la vez, es una posibilidad de construcción del Reino con alcances escatológicos.

Palabras claves: Poder, teología del poder, corrupción, antropología trascendental, construcción del Reino.

\section{A theological look at power. \\ Contributions to the transcendental anthropological discernment of corruption}

\begin{abstract}
Abtracts
The following article intends to make a theological reading of power following Karl Rahner in his conception of it as a gift, task and possibility. Power is a divine gift for the human being who participates in the power of God, however when exercised it can be corrupted and loses the purpose for what is delivered. In this way, the bad exercise of power has repercussions for both the person and society, serious consequences, that is why it is necessary to take responsibility for each action. In this sense, the exercise of power is an essential task for life in society and at the same time, it is a possibility of building the Kingdom with eschatological scope.
\end{abstract}

Key words: Power, theology of power, corruption, transcendental anthropology, construction of the Kingdom.

* Doctor en Teología Práctica por la Universidad Pontificia de Salamanca, España. Magíster en Teología dogmática por la Pontificia Universidad Católica de Chile. Licenciado en Ciencias Religiosas y Profesor de Religión por la Pontificia Universidad Católica de Valparaíso. Actualmente se desempeña como académico de la Facultad Eclesiástica de Teología de la Pontificia Universidad Católica de Valparaíso. Es autor del libro, fruto de su tesis doctoral, La responsabilidad social en el pensamiento de San Alberto Hurtado Cruchaga (2017). 


\section{INTRODUCCIÓN}

Cuando desde la teología se alude al concepto de poder, o potestas, se hace referencia al poder de Dios, que siempre es pensado como un ejercicio justo y desarrollado para el beneficio de la humanidad. Este atributo de la condición divina es muy loable, pero cuando ese poder desciende al ejercicio que desarrollan los seres humanos por participación del poder divino, esta acción no siempre se ejecuta de forma justa no sólo para la persona sino también para toda la sociedad.

Paralelamente, durante estos últimos años en el mundo entero, se ha desplegado la pandemia de la corrupción, que ha afectado directamente a las personas y al desarrollo de los pueblos. Diversos estudios han relacionado el círculo vicioso entre poder y corrupción (Hernández, 2017; Martínez, 2009), donde su correlación parece tan estrecha que no pueden existir una sin la otra. Según Putz, por las características que tiene el poder de ser limitado es que las personas buscan conservarlo y ampliarlo, y es por esto que "el deseo de mayor poder (instinto de poder) va asociado a la posibilidad de corrupción del poderoso" (Putz, 1993: 467). A su vez, si se define la corrupción, en un sentido amplio se puede explicar como el "ámbito interpersonal o social donde una o varias personas utilizan su poder o lugar de privilegio con la finalidad de obtener de manera ilícita ciertas ventajas o beneficios personales" (Correa, 2017: 76).

También se podría afirmar que la corrupción siempre ha existido, el problema es que se está constituyendo en un fenómeno globalizado de nefastas consecuencias y es tan importante para la sociedad que incluso se coordinó un encuentro en el Vaticano sobre el tema, organizado por el Pontificio Consejo Justicia y Paz (2006), enmarcando la corrupción principalmente en el ámbito de la economía y la política. A su vez, el Papa Francisco (2018), al ser consultado por el tema, lo ha descrito como una ciénaga de la cual es muy difícil salir, no sólo para el que lo provoca, sino también para aquellos que involucra. Él mismo ha reconocido, además, que en la Iglesia ha habido casos de corrupción, ya que este fenómeno, según Pasquino (2015), no se reduce a ciertos ambientes, sino que la corrupción está formando parte de la vida privada, ciudadana e institucional.

$\mathrm{Al}$ respecto, Correa (2017) afirma que los chilenos han sido víctima de la corrupción de las empresas, en el financiamiento de la política, casos de colusión, pero también se puede dar en ámbitos más domésticos como las juntas de vecinos, el club deportivo o el sindicato. Pero junto a lo anterior, se ha dado el fenómeno de corrupción en instituciones que parecían intachables como carabineros, el ejército y la iglesia, por lo que la probidad que caracterizó a Chile durante décadas, según Orellana (2007), hoy es un 
reflejo del pasado que si no se le enfrenta seguirá proliferando exponencialmente.

Ante esta situación, la corrupción viene a ser un tema país; de hecho, la presidenta Bachelet constituyó el Consejo asesor presidencial contra los conflictos de interés, el tráfico de influencias y la corrupción (2015), lo que permitió levantar algunos proyectos de ley, sin embargo, gran parte de las recomendaciones del Informe, según la entrevista de la periodista Fernández (2018) realizada al presidente del consejo Eduardo Engels, continúan pendientes.

De lo dicho hasta aquí, ciertamente, que la administración del poder por parte del ser humano es un tema al cual se debe prestar atención, puesto que el ejercicio de esta cualidad desata consecuencias que trascienden a la persona misma afectando directamente a la sociedad y a sus integrantes, permitiendo el despliegue de la corrupción. Es por este motivo que el artículo pretende aportar al tema desde la teología del poder, que se alimenta de la teología de la creación y la antropología teológica. La tesis que sustenta el artículo se fundamenta en que el poder es un atributo dado por Dios al ser humano, donde el mal uso de éste corrompe su ejercicio y por tanto el entorno, de allí que el poder, además de ser un “don”, es una "tarea" y una "posibilidad" para el ser humano (Rahner, 2002: 454).

$\mathrm{El}$ artículo sigue un método monográfico, donde el texto fundamental es la Teología del poder de Karl Rahner (2002), el cual publica en el año 1960. Desde este texto, se infieren las categorías de análisis sobre el poder como don, tarea y posibilidad, para desde allí confrontar con otros teólogos, documentos del magisterio y problematizar sus afirmaciones con algunos autores contemporáneos que tratan el tema.

El alcance del artículo considera la vida de la iglesia y la sociedad. Ciertamente, una teología del poder es necesaria para la institución eclesiástica en cuanto que posibilita el escrutarse a sí misma y, al mismo tiempo, puede ayudar a la formación del clero, religiosos, religiosas y laicos, que en razón de su misión dentro del pueblo de Dios se les encarga una tarea donde deben ejercer el poder. Al mismo tiempo, una teología del poder, puede ser un aporte desde una visión humanista cristiana que dialoga con una sociedad plural que urgentemente debe buscar caminos para un correcto uso del poder y así reconstruirse desde las confianzas, para desterrar la corrupción.

El artículo, se ordena siguiendo las coordenadas de Rahner, por tanto, en el primer apartado se desarrollará el tema del poder como don de Dios; mientras que en el segundo se trata la temática del poder como tarea de humanización y, finalmente se despliega la cuestión del poder como posibilidad de construcción del Reino. 


\section{PODER COMO DON DE DIOS}

Rahner, inicia su construcción de la teología del poder, considerando que uno de los atributos de Dios es ser todopoderoso o, como él prefiere llamarlo, "solo-poderoso" (Rahner, 2002: 449). Por tanto, si Dios es el solo-poderoso, quiere decir que, aunque Dios haga partícipe al ser humano de su poder, el único que ejerce en plenitud este atributo es Dios mismo, tanto como facultad de ejercicio del poder, como desde el punto de vista moral, porque Dios es la suprema bondad.

Ahora bien, el ser humano en su condición creatural recibe de parte de Dios como un componente de su ser el poder, por lo que sería parte de la autocomunicación de Dios. Para Rahner (1976), el concepto de autocomunicación es el centro de su teología pues con esta acción, Dios se comunica a sí mismo y se dona a sí mismo, constituyéndose en el componente más esencial del ser humano. Dios con la autocomunicación transforma al hombre, otorgándole la posibilidad de acceder a un encuentro personal y percibir la profundidad de su subjetividad y de su experiencia trascendental.

Rahner (1972) sostiene que la condición de posibilidad para la autocomunicación de Dios es el acto de la creación. Por tanto, la creación entera con la naturaleza y su historia, son un momento de la gracia y, por tanto, un espacio para la manifestación de Dios. El teólogo alemán, cuando desarrolla su teología, va tejiendo una paradoja que se entiende sólo desde el misterio, pues Dios al crear, está radicalmente distante de la creatura porque es totalmente diferente al ser humano, pero al mismo tiempo, es lo más cercano al hombre mismo pues, el acto de la creación, no se detiene en el transcurso de su vida histórica categorial, sino que se extiende más allá de estas limitantes históricas (Rahner, 1976).

Esta alusión a temáticas características de la teología rahneriana, no tienen otro propósito que enmarcar la definición de poder que el teólogo alemán desarrolla desde el presupuesto que no es un concepto unívoco. $\mathrm{Al}$ respecto define el poder como la:

autoafirmación propia de un ente determinado, la resistencia y, de ahí, la posibilidad activa que necesariamente le es propia, de intervenir desde sí y sin la aprobación previa del otro en el estado real de ese otro modificándolo, está claro de antemano que todo ente, por el simple hecho de ser —en sí y frente a los otros - tiene también, en cierto sentido y grado, poder (Rahner, 2002: 449-450). 
Rahner (2002) no condena el uso del poder pues lo considera un valor positivo creado por Dios, el problema se suscita cuando este poder donado se ejerce en forma física y corporal, lo que lleva a interferir en la existencia del otro, pues cada uno trasciende fuera de sí por medio de su actuar corporal interfiriendo o afectando la vida de los demás seres humanos. De allí se entiende que el ejercicio del poder sea un aspecto gravitante en la vida personal y social.

Autores clásicos como Hobbes (2017), sostienen que el poder consistiría en las posibilidades que el hombre tiene para procurarse los recursos para su sustento, ello conlleva una serie de alcances que ubican al poder en el ámbito social y, por sobre todo, económico. Pues, para este autor, el ser humano es valorado y apreciado por la estima de los demás sin importar sus potencialidades. Esta lectura antropológica, contrasta drásticamente con la postura de Rahner (2002) en el sentido que todos los seres humanos poseen desde su creación el don del poder divino y no, como afirma Hobbes, que el poder es algo que se gana externamente, lo cual se "expresa en cargos de mando, judicatura, empleos públicos, o en los nombres y títulos introducidos para distinguir semejantes valores" (Hobbes, 2017: 84).

Junto con ser don, Rahner (2002) sostiene que el poder se manifiesta en las relaciones interpersonales de manera evidente. Pues cada uno al hacer ejercicio de su libertad de una u otra forma está interfiriendo y afectando la vida de los otros. $\mathrm{Al}$ respecto, un autor más contemporáneo como Holloway (2002), plantea que el poder está en el mismo ser humano y que, principalmente, se constituye en un "poder hacer" que eminentemente tiene la característica de ser social, no podría darse un hacer individual. El problema, señala el autor, es cuando este "poder hacer" se transforma en poder sobre, de allí que: "mientras el poder-hacer es un proceso de unir, el unir mi hacer con el hacer de otros, el ejercicio del poder-sobre es separación" (Holloway, 2002: 50).

Ahora bien, el poder por sí mismo no posee una cualidad moral, es decir no es malo ni bueno, según Putz (1993: 467), el poder tiene un "carácter instrumental", donde cada persona ejerce su propio autodominio o ejerce poder sobre otro, optando por formas de actuar que renueva el horizonte del saber crear, suscitar y valorar; considerando que los cargos de poder que una persona pueda ejercer en su vida son temporales y extraordinarios, donde en el tiempo común de la vida lo que queda es la persona con sus aprendizajes, con sus relaciones y sus intenciones. Desde la teología rahneriana (Meis, 1993), la cualidad moral del poder viene dado por la bondad del creador, sin embargo, en el caso de la creatura racional, su 
ejercicio se ve dañado por la presencia del pecado original, pues este acontecimiento interpondría una barrera al ejercicio pleno y bondadoso del poder por parte de la humanidad.

Esta realidad, del poder que se corrompe a causa del pecado, se puede apreciar en la historia de la Iglesia, cuando el poder se comprendió como un don de Dios y se tendió a igualar la autoridad del monarca con la autoridad divina representada por el Papa, afirmando que ambos poderes proceden directamente de Dios y que sus decisiones serían unívocas e irrevocables; el choque de estos poderes es lo que se llamó la lucha de las investiduras (Sánchez, 2005). Por su parte, ad intra eclesiae el dogma de la infalibilidad, proclamado en el Concilio Vaticano I (Concilio Vaticano II, 2000a), por lo general es comprendido por los mismos católicos y la opinión pública como un poder especial entregado por Dios al Papa para no equivocarse, el problema es cuando la propia jerarquía lo percibe de ese modo sin considerar el sensus fidei como sustento de dicha infalibilidad, constituyéndose en un poder vertical y hegemónico (Francisco, 2013).

En la actualidad, la ciudadanía se opone al poder asimétrico. Sin embargo, hoy surgen nuevas divinizaciones del poder donde éste no viene de Dios, sino de personas o conglomerados que ostentan y conquistan el poder (Domingo Moratalla, 2014). De esta manera, la gran problemática de nuestro tiempo son los reduccionismos a los cuales se somete el ser humano por los distintos enfoques de la vida social, pues para algunos el poder sólo se manifiesta en un nivel político, ejerciendo el hombre sus cualidades en conglomerados que se unen por una causa de gobierno ciudadano (Höffe, 2007); para otros es un poder de tipo social, que se manifiesta a través de las distintas expresiones de movimientos sociales que reclaman sus derechos por una vida mejor (Garcés, 2012); pero, a decir verdad, la más profunda y potente reducción ha sido la economicista, que entiende al ser humano como un ente económico que debe ser valorado por su poder adquisitivo, su productividad, su eficiencia y eficacia, en definitiva por lo que posee (Bauman, 2007). En estas visiones, el poder también se adquiere y puede ser acrecentado, por lo que no es considerado como connatural al ser humano.

De allí que el ejercicio del poder, desde un punto de vista teológico de tradición católica, se convierte en una tarea que intenta realizar su ejercicio para el bien de la humanidad en su conjunto, porque "junto al fenómeno del poder ontológico, se nos presenta, como inevitable signo del mismo, el poder social y político" (Flecha, 2007: 334). 


\section{EL PODER COMO TAREA DE HUMANIZACIÓN}

El poder, al ser un don de Dios para el ser humano, se convierte en una tarea para ejercerlo con propiedad y de buena forma que se fundamenta en el "carácter histórico del hombre definido como el ser en diálogo temporal y espacial con el Otro, los otros y con el cosmos" (Galindo, 1996: 395).

En sus planteamientos Rahner (2002) señala que como don de Dios y, para su buen ejercicio, el poder debe estar iluminado por la verdad y el amor. Estas dos cualidades garantizan que el ejercicio del poder cause un impacto positivo al ejercicio de la libertad, porque "poder y libertad son realidades dependientes dialéctica y recíprocamente dependientes la una de la otra" (Rahner, 2002: 457).

De este modo el poder, al ser una creación buena de Dios y ejercida por el ser humano bajo las coordenadas de la verdad y el amor, se tornaría en una actividad que redunda en beneficio propio y de la sociedad. Es decir, se podría afirmar desde la teología del poder de Rahner (2002) que, el proyecto de la creación de Dios, previo el pecado original, es un ejercicio del poder que debería ser en sí íntegro y libre de concupiscencia, realizadas desde la verdad y el amor, dimensiones que se constituyen en auténticas potencialidades de la libertad.

Lo anterior, se comprende en el contexto de la protohistoria, pero no es la realidad que la humanidad conoce pues la historia categorial ha contado desde sus inicios con la existencia del pecado original. Rahner (2002), manifiesta que el pecado es quien afecta y desvirtúa el poder como bien entregado por Dios al hombre, pues influye directamente en la práctica del poder que realizan los seres humanos, bloqueando tanto la verdad y el amor en el ejercicio de la libertad.

El pecado, por tanto, nubla la libertad y el ser humano experimenta el dualismo entre lo que quiere ser y lo que efectivamente es. Ahora bien, es necesario considerar que se trata de una libertad afectada y es por este motivo que experimenta la fuerza de poderes externos que van contra su decisión libre y lo hace sufrir; es la experiencia de la concupiscencia y sumisión del dolor, es una forma de la manifestación del pecado que no debe confundirse con el pecado mismo. Esta visión de Rahner (2002), tiene su fundamento, aunque él no lo mencione explícitamente, en la tradición paulina expresada en la Carta a los romanos cuando Pablo manifiesta esta tensión entre la libertad y la ley del pecado. Ambas permiten que el ser humano realice obras, pero la paradoja está en que la persona experimenta en la profundidad de su existencia que "no hago lo que quiero, sino que hago lo que aborrezco" ( $\mathrm{Rm} 7,15)$, porque "en realidad, ya no soy yo 
quien obra, sino el pecado que habita en mí" (Rm 7, 17), entonces descubre una premisa que "aun queriendo hacer el bien, es el mal el que se me presenta” (Rm 7, 21).

El teólogo alemán, interpreta y sintetiza la antropología paulina afirmando que toda creatura tiene las características de ser "ambivalente, pervertible y profanable" (Rahner, 2002: 454) en los distintos atributos que Dios le ha donado, por tanto, frente al poder se aplica lo mismo. De modo que el poder es bueno en sí porque es gracia de Dios, pero ambivalente, porque el pecado interfiere en el ejercicio del poder, entendiendo el pecado como una acción y decisión contraria a la voluntad de Dios, por tanto, en la praxis del poder el hombre "puede disponer de ese autodominio para el bien que para el mal" (De la Pienda, 1982: 370). Por eso el poder es pervertible porque es don de Dios y por ese motivo "es del todo indebido y que sólo se explica desde la total gratuidad, pueden erosionarse paulatinamente conforme fluye la vida" (Castelao, 2013: 81). Finalmente, el poder es profanable porque equivoca el camino y se hace contrario a la voluntad de Dios y es por este motivo que el poder no es salvíficamente irrelevante, sino que su buen ejercicio permite el acceso a la salvación o, de lo contrario su ejercicio inadecuado lleva a la condenación, por lo que posee una dimensión escatológica en tanto "respuesta o negación al proceso creador de Dios" (Galeano, 2016: 383).

En este sentido es interesante constatar que muchos de los sistemas económicos, sociales y políticos, inician su elaboración conceptual del poder desde una realidad que no considera la incapacidad del ser humano de pervertirse. $\mathrm{O}$, dicho de otra manera, de controlar sus impulsos hacia una autosatisfacción a partir de su deseo infinito de satisfacer sus propias necesidades, desconociendo las necesidades de los otros; lo mismo sucede con la vida social, donde no se buscaría el bien común sino el bien particular de los suyos, provocando el nepotismo. Al respecto desde Max Weber el poder se explica desde una relación social con su matices asimétricos, normativos y de interdependencia (Lukes, 2007); ha sido la psicología la que ha instalado el poder incorporándolo a la estructura del ser humano como un modo de vincularse con el otro, donde su valoración moral va a depender de la elección de los bienes por los cuales se opte ya sea de tipo egocéntrico o altruistas, y desde lo cual se puede considerar un buen o mal ejercicio del poder (Benbenaste, Delfino \& Vitale, 2006; Pinker, 2012).

Continuando con la reflexión teológica, ella considera que el poder necesita ser redimido, al igual que otras dimensiones ontológicas que Dios ha regalo al ser humano. Siguiendo con el texto de la Carta a los romanos, san Pablo contempla la paradoja del ser humano, exclamando: “ $¡ P o b r e ~ d e$ mí! ¿Quién me librará de este cuerpo que me lleva a la muerte? ¡Gracias sean dadas a Dios por Jesucristo nuestro Señor!” (Rm 7,24-25). Rahner 
(2002) señala que es necesaria la gracia de Cristo como ayuda sobrenatural para el buen ejercicio del poder. De esta manera, cuando el teólogo alemán (Rahner, 1976) plantea que el poder debe estar enraizado en la verdad, se está refiriendo a la verdad de la autocomunicación de Dios donde la encarnación es el punto irreversible de esta autocomunicación y, a su vez, con perspectiva escatológica ya que el ser humano gozará de la plenitud de la autocomunicación en la visión beatífica (Aros, 2011a). De allí que Rahner (2002) sostenga que desde la teología del poder la dimensión escatológica debería estar presente como una forma de discernir el tiempo categorial y a la vez sopesar lo realmente importante de la existencia. Esto lo fundamenta explícitamente en la enseñanza de San Pablo en la Carta a los corintios:

Os digo, pues, hermanos: el tiempo es corto. Por tanto, los que tienen mujer, vivan como si no la tuviesen. Los que lloran, como si no llorasen. Los que están alegres, como si no lo estuviesen. Los que compran, como si no poseyesen. Los que disfrutan del mundo, como si no disfrutasen. Porque la apariencia de este mundo pasa (1Cor 7, 29-31).

El poder es temporal y es necesario ejercerlo desde esta perspectiva y a la vez circunscribirlo al contexto del mundo pasajero, porque aquello que le interesa enseñar a San Pablo a la comunidad de los Corintios es que vivan en la perspectiva de ser ciudadanos del cielo para que alcancen las moradas eternas (2 Cor 5,1). Es por esto que, se señalaba al principio del apartado, que Rahner (2002) sostenía que el poder debería ejercerse en el horizonte de la verdad y el amor, porque el ejercicio del poder es interpersonal. Así, cuando actúo, estoy haciendo una interferencia en el mundo del otro, al modo como Dios se autocomunica con el ser humano que, al ser pura gratuidad, es el acto de amor más sublime que la persona puede experimentar (Rahner, 1976).

Ahora bien, como señala Rahner (2002), las personas están tan acostumbradas a que el otro actúe, que ya parece algo natural hasta que se empieza a calibrar la acción del otro y considerar el carácter moral del actuar. Es por este motivo que la teología del poder posee su constatación práctica en el ámbito de la teología moral porque cuando actúo modifico la realidad del otro.

Del mismo modo, como anteriormente se aludió al pecado original que considera la concupiscencia, la moral cristiana reconoce que el ser humano puede corromperse en sus acciones. Esto significa que el ejercicio del poder siempre va a generar conflictos a nivel personal, comunitario y social, porque en menor o mayor grado, transformo la vida del otro. No 
siempre se acierta en el ejercicio del poder, pero la persona puede aprender de sus desaciertos.

Esta praxis moral de la teología del poder, tiene como sustento la antropología trascendental, pues "el que obra poderosa y libremente se extiende más allá de sí mismo" (Rahner, 2002: 463). Esta capacidad de trascendencia, en el ser humano, es una cualidad que le permite ir más allá de sus propios límites y de sus propias incapacidades, concibiendo la vida desde su posibilidad de avanzar más allá de su propio instinto y de su propio ser. Al punto de considerar que la vida no se acaba en el presente, sino que se proyecta a una vida posterior más allá de las coordenadas de espacio-tiempo (Aros, 2016). En este sentido, el hombre, es el único ser al interior de la creación que posee una coordenada de futuro que lo proyecta hacia una realidad trascendente y comprende que el otro también tiene derecho a vivir su vida de esta manera.

Por tanto, el ser humano que ejerce el poder con verdad y amor "está siempre afectado y humillado por la dignidad libre del otro frente al cual se usa ese poder" (Rahner, 2002: 467). La dimensión trascendente del ser humano, lo hace ser consciente de que su vida está referida a Dios y por lo mismo al otro como creatura (Aros, 2011b); por tanto, en el ejercicio del poder, procurará que sus actos sean metódicos, sutiles y delicados. Para expresar esto, Rahner (2002) utiliza la imagen de un cirujano con el paciente y señala que quien vive así el poder lo redime y lo santifica.

Según Rahner (2020), este sería el modo de ejercer el poder con sabiduría. Debe partir del presupuesto de la comprensión de lo efímero y limitado que es el poder asociado a un cargo, a partir de ello, reconoce sus limitaciones en la comprensión de la realidad, se deja asesorar por otros que están en consenso y disenso a su propia mirada y aceptan las correcciones necesarias para llevar adelante un proyecto donde todos y cada uno se sientan partícipes. El sabio que ejerce el poder no destruye al otro, no lo convierte en objeto, no ocupa la mentira como argumento y reconoce siempre la dignidad personal de cada uno de los integrantes de la comunidad.

Por el contrario, el poder necio y soberbio, se inicia con un presupuesto falso engañándose a sí mismo, pues se autoafirma en su propio criterio como criterio de verdad aduciendo un poder divino fundamentado en el poder de Dios, levantándose como único criterio de la verdad que lo lleva, necesariamente, a pervertir el poder donado por Dios para el bien común y convertirlo en una acción ególatra, egocéntrica y nepótica. También, el poder necio es soberbio, pues no reconoce que el poder finito es entregado sólo para algunas funciones y que existen otros que también pueden ejercerlo, incluso dotados de mejores cualidades. Es más, cuando 
estas habilidades no están, tienen como consecuencia que la toma de decisiones y el actuar, se hace de manera errónea lo que muchas veces decreta el fracaso de la misión encomendada. El poder mal ejercido obnubila la razón y la persona no es capaz de ver la realidad más allá de su propia autocomprensión, no acepta miradas diversas que amplíen su campo de visión, con lo cual todas sus acciones están marcadas y sesgadas por su discernimiento miope del cual no corregirá, incluso, si lo llegan a remover de su cargo (Goleman, Boyatzis \& McKee, 2010).

\section{EL PODER COMO POSIBILIDAD DE CONSTRUIR EL REINO}

Para Rahner (1976), el ser humano se levanta como una pregunta abierta que posee posibilidades infinitas de respuestas en las diversas dimensiones de su vida. Desde esta perspectiva, el ejercicio del poder es una de esas realidades humanas que debe ser asumida en su complejidad, multidimensionalidad y asumiendo la responsabilidad de dicha acción.

Como ya se ha señalado, la necesidad de desplegar el poder es necesario aplicarlo con sabiduría y por tanto referida al prójimo y desde ahí, a la sociedad en su conjunto. Si bien es cierto, en el escrito sobre la teología del poder, Rahner (2002) no señala explícitamente como posibilidad la construcción del Reino y de una praxis social según la voluntad de Dios, se opta por realizar este quiebre de ir más allá del autor puesto que ha entregado todos los fundamentos para dar este salto cualitativo. Así, en este apartado se propone desarrollar la praxis social de la teología del poder en base a los tres principios fundamentales que de la enseñanza social de la Iglesia se desprenden, a saber, bien común, justicia y amor (Pontificio Consejo Justicia y Paz, 2014; Hurtado, 2004).

De esta manera, si el poder es un don, entonces el tener la oportunidad de ejercer el poder significa donarse en el amor, colocando al servicio los talentos de cada persona llamada al diálogo con Dios por la autocomunicación. Esto significa que el trato y el ejercicio del poder hacia el otro debe estar a la altura de su dignidad, sólo así esa relación se constituye en un circulo virtuoso de confianza, respeto y consideración por las individualidades, visibilizando y proyectando los talentos de otros, es decir, ese poder se transforma en fuente multiplicadora de dones (Goleman, Boyatzis \& McKee, 2010). Esto es lo que propicia una persona que ejerce el poder con liderazgo, por tanto, una clave de ejercicio del poder en base al amor podría encontrarse en las actuales teorías de coaching (Fischman, 2014; Covey, 2009; Maxwell, 2004; Sandoval, 2016; Sharma, 2012).

Para ejercer el poder desde la perspectiva del don y del amor, la Doctrina social de la Iglesia desarrolla el concepto de amistad civil, que se fundamenta en el valor de la fraternidad (Pontificio Consejo Justicia y Paz, 
2014), que como señala Gaudium et Spes (Concilio Vaticano II, 2000b), la fraternidad permite y consolida un diálogo sincero entre todos los pueblos. Desde una esfera filosófica contemporánea Höffe (2008), señala la necesidad de replantearse el intercambio cultural y social desde una perspectiva de apertura al diálogo y de valorización de las identidades diferentes. En definitiva, como señala Benedicto XVI (2009), lo que está en juego es "la necesidad de alcanzar una auténtica fraternidad" (n. 20).

Así, quien ostente el poder a distintos niveles de la sociedad, necesita de diversos instrumentos para conseguir habilidades que le permitan un buen ejercicio del poder en base a la comunicación efectiva, tales como la asertividad, la escucha activa, la empatía, la autenticidad y la sabiduría de la sencillez (Flores, 2014; Abarca, 2004; Goleman, 2013).

En este espacio, la asertividad permite un ejercicio del poder situado, sincero, honesto, en donde el contexto y el momento se constituye en una expresión de emociones reguladas por un saber estar con el otro. Actitudes como decir correctamente, solicitar lo que se necesita y agradecer, genera prestigio social y construye el espacio de convivencia. El peligro es situarse en los extremos, es decir, o desde la pasividad o desde la agresividad, impidiendo la sana convivencia. El ideal, es que las relaciones de poder se puedan trabajar desde el punto medio de la aserción, para que la comunicación entre los integrantes de cualquier comunidad social pueda fluir fraternalmente.

$\mathrm{Al}$ mismo tiempo, la escucha activa se constituye en un puente efectivo de resolución de conflictos, que se adquiere a través de la experiencia del encuentro con el otro, en la situación de vida que se encuentre. Estar preparado para escuchar requiere estar presto a colocarse en una actitud física y mental de leer al otro, no solo con los oídos, sino con el cuerpo. Esta disposición, significa que los gestos, la mirada, los movimientos van aportando a favorecer un clima de confianza y posibilitador de aceptación, puesto que no juzga, no descalifica, no impone juicios, más bien, coloca al servicio la reciprocidad como un don en acción.

En el mismo sentido, la empatía refiere al ejercicio afectivo del poder considerando y comprendiendo al otro como legitimo otro, con sus valores, debilidades y potencialidades. Este ejercicio humanizador permite construir una relación a escala humana en donde la persona con todo su ser se muestra completa ante otro, recogiendo lo esencial y predisponiendo a la colaboración y a las relaciones humanas fraternas.

Asimismo, la autenticidad como una virtud personal, que aporta al ejercicio del poder, significa responsabilidad del ser uno mismo, considerando la alteridad como una convicción profunda de que la palabra y la acción coherente promueve la verdad y aleja la falsedad. Despojar las más- 
caras significa derribar las falsas expectativas que se levantan como barreras materiales y simbólicas que no permiten las relaciones saludables. Entonces la autenticidad significa construir desde perspectivas innovadoras y fecundas, aportando en el despliegue de los talentos de los otros, destacando sus fortalezas, realizando la corrección fraterna y honesta.

Finalmente, la sabiduría de la sencillez se presenta como sanadora del saber vivir en el mundo de la vida, operando desde el justo medio, permitiendo el milagro de la fe y confianza en la construcción de una sociedad que se reconoce y se mira sin prejuicios considerando que "a cada cual se le otorga la manifestación del Espíritu para provecho común” (1Cor 12, 7).

Otro aspecto que considera la enseñanza social de la Iglesia para la construcción del Reino es bajo el prisma del bien común y la justicia, cuyo eje se concentra en la custodia de la dignidad de la persona humana. Así, el buen ejercicio del poder posibilita la construcción de una sociedad justa y la búsqueda del bien común, previniendo todo menoscabo de la dignidad humana que el contexto cultural tiende a desfavorecer (Latouche, 2014). Esto lo advierten constantemente los documentos de la Doctrina social de la Iglesia que disciernen desde diversos contextos y perspectivas las realidades sociales. En el caso latinoamericano, los obispos reunidos en Aparecida lo expresaban de esta manera:

La cultura actual tiende a proponer estilos de ser y de vivir contrarios a la naturaleza y dignidad del ser humano. El impacto dominante de los ídolos del poder, la riqueza y el placer efímero se han transformado, por encima del valor de la persona, en la norma máxima de funcionamiento y el criterio decisivo en la organización social (CELAM, 2007: n. 387).

En esta misma línea de reflexión, Latouche \& Harpagès (2011) invitan a transformar el modelo de desarrollo ilimitado imperante por un modelo de decrecimiento donde el ser humano sea el eje central del funcionamiento social y económico, dejando atrás el sujeto que consume sin límite y globalizadamente. Al mismo tiempo Latouche (2012) afirma que la felicidad en las cosas simples y sencillas de la vida sea el motor de toda actividad humana, invitando a la sencillez de la vida social y económica, y a un consumo moderado de los bienes.

De este modo, las personas cuando ejercen el poder están llamadas a discernir los signos de los tiempos, alentando hacia el bien común y construyendo nuevas rutas para favorecer la humanización de una sociedad más justa. Justicia y bienestar son dos caras de la misma moneda, propiciando en la existencia personal y social, alternativas y horizontes posibles 
de acercarse al Reino. Así, la persona "comprende la propia dignidad trascendente, aprende a no contentarse consigo mismo y a salir al encuentro del otro en una red de relaciones cada vez más auténticamente humanas" (Vaticano II, 2000b: n. 23).

La consideración de la dignidad humana requiere el compromiso irrestricto con aquellos que sufren, los más pobres y débiles, posicionándolos como seres únicos, irrepetibles y valiosos, siendo sujetos de derechos y de justicia social. Por tanto, toda relación de poder debe respetar y promover "la dignidad de la persona humana, su entera vocación y el bien de toda la sociedad por que el hombre es el autor, el centro y el fin de toda la vida económico-social" (Concilio Vaticano II, 2000b: n. 63). De este modo, para respetar la dignidad de la persona y de los ciudadanos es necesario buscar el bien común en cuanto "conjunto de condiciones de la vida social que hacen posible a las asociaciones y a cada uno de sus miembros el logro más pleno y más fácil de la propia perfección" (Concilio Vaticano II, 2000b: n. 26).

Ahora bien, el mal ejercicio del poder lleva a la corrupción de las instituciones, utilizándolas para el beneficio personal y causando graves daños a los pueblos. Como señala el Pontificio Consejo Justicia y paz (2006: 5a): "La corrupción se enumera entre las causas que en mayor medida concurren a determinar el subdesarrollo y la pobreza y, en ocasiones, está presente también al interno de los procesos mismos de ayuda a los países pobres". Lo peor es que estos procesos se realizan muchas veces en el marco de la legalidad de un país, de modo que todos estos abusos a la dignidad de la persona y la invisibilización del cuidado de los bienes de todos, quedan en una desprotección total de parte de los ciudadanos. Esto porque "la corrupción priva a los pueblos de un bien común fundamental, el de la legalidad: respeto de las reglas, funcionamiento correcto de las instituciones económicas y políticas, transparencia" (Pontificio Consejo Justicia y paz, 2006: 5b).

$\mathrm{Al}$ respecto, cabe señalar que Alberto Hurtado ya preveía el nexo inapropiado entre legalidad y liberalismo:

El capitalismo cree poseer todos los derechos. La justicia no parece estar sino de su lado. Teniendo el derecho se puede tener todo. Ya ha oprimido a tantos desgraciados que no se han levantado, ha engañado a tantos que le han confiado sus ahorros y han seguido confiándoselos, impuesto tantas leyes que eran favorables a sus designios, corrompidos tantos políticos (Hurtado, 2005: 38). 
De este modo se puede apreciar que un ejercicio del poder ilimitado y respaldado por organismos corruptos conduce a una sociedad que evidencia síntomas de descomposición que afectan sobre todo a los más vulnerables.

Por su parte, para realizar un buen ejercicio del poder es necesario buscar la justicia, pues es innegable la relación existente entre corrupción e injusticia social. Es por este motivo que una teología del poder debe considerar la justicia como una posibilidad de construcción de la ciudadanía, por medio de la cultura del resguardo, siendo la denuncia una forma de develar los abusos, la corrupción y el encubrimiento, que se ensaña sobre todo con los más débiles, los pobres, los desprotegidos. El promover la justicia significa realizar un cambio profundo de los modos de vivir y de considerar a las personas, las comunidades y los pueblos, a través del trabajo decente y sueldos dignos, lo que permitiría establecer un piso ético común, en donde las riquezas culturales, materiales, educativas y sociales sean repartidas equitativamente. Lo anterior, pavimenta o funda las bases para la construcción de la paz, la convivencia pacífica y fraterna. La justicia requiere una renovación individual de la caridad, mirar con ojos nuevos, con compromiso, queriendo implicarse en el cambio social. Respetando y considerando las diversidades en pos del bien común que se renueva.

Finalmente, un aspecto central para que el poder se constituya como posibilidad de construcción del Reino es propiciar la formación de los cristianos y de todos los hombres de buena voluntad, en el ejercicio del poder. Pues, como se señaló en los apartados anteriores, la teología del poder considera que todos los seres humanos ejercen el poder trascendiendo hacia la vida de otros. Por tanto, no es necesario tener una función para ejercitar el poder, por el sólo hecho de existir ya el ser humano establece vínculos de domino. El asunto está en cómo ejercer el poder como don de Dios, y como todo en la vida del ser humano, la condición de poder necesita ser educada.

Es por esto que una pedagogía teológica del poder, debería considerar la formación de habilidades que fortalezcan las relaciones equitativas, considerando que el líder debe servir, no subyugar, que debe compartir el poder de manera distributiva y simétrica considerando los talentos que cada cual posee (Goleman, 2013). Por tanto, se transforman los campos semánticos: de intervención se cambia por acompañar; de opresión por amparar; de jerarquía por compartir; de injusticia por justicia, de exclusión por reconocimiento.

Esta consideración pedagógica de la teología del poder cobra sentido en un mundo donde se ejerce la violencia estructural, las guerras, los genocidios, la trata de personas, el crimen de género, la discriminación, el individualismo, la desconfianza, los fundamentalismos, los integrismos, 
entre otros; todas problemáticas derivadas de un poder mal ejercido que corrompe los cimientos de la sociedad y de la Iglesia (Pinker, 2012).

\section{CONCLUSIONES}

Cuando en la sociedad se trata el tema del poder, hay que considerar que esta cualidad del hombre es vista desde múltiples dimensiones y que muchas veces parece ser una capacidad entregada por otros. Por lo general, no siempre es entendida como perteneciente a cada uno de los seres humanos, lo que permite que muchos no se responsabilicen de sus acciones y relaciones que se establecen como vínculos de poder con otros.

En muchas oportunidades se puede acceder a personas que creen ser intrascendentes, que sus acciones o decisiones no afectan a nadie más que a ellos y a su círculo cercano, de esta forma, se niega una cualidad antropológica fundamental, pues se reduce la acción humana a simples actos que terminan una vez realizados y no se toman en cuenta las repercusiones que cada acontecimiento tiene para la persona misma y para la humanidad en general. Entre las razones de no considerar a la persona como un ser trascendente, se encuentran el inmediatismo económico que piensa al ser humano como un ente productor y consumidor de bienes y servicios, reduciendo de esta forma a la persona a ser sujeto económico.

Desde el punto de vista teológico el único que posee el poder en plenitud es Dios. El ser humano lo que hace es participar del poder de su creador, por tanto, el poder que puede ejercer el ser humano posee los límites de la creatura racional, delimitado por un tiempo y un espacio. Por tanto, toda persona ejerce un poder creatural.

Según la teología del poder de Rahner, en el caso del ser humano este poder puede desviarse de la finalidad a la cual Dios lo había destinado. Aquí es el pecado quien interfiere en el ejercicio lícito del poder por parte del hombre, por tanto, el poder necesita ser redimido por la gracia de Cristo. En este sentido el poder es don y tarea, que se inspira en el amor como centro vital y enraizada en la verdad de la condición creatural. Al respecto una adecuada teología del poder debería considerar un desarrollo interdisciplinar del pecado personal, social y estructural (Martínez, 2011).

Tener poder significa ser portadores de la obra de Dios, que permite realizar acciones inéditas, manifestándose en la vida cotidiana. De allí que el justo accionar del poder personal es trascendente para la vida social del cual todos somos responsables. Ciertamente, habrán funciones en la vida social donde el alcance del ejercicio del poder sea más reducido para algunos y más amplio para otros, pero en ambos casos cuyo norte es la posibilidad de la construcción de la sociedad basada en el bien común, la justicia y la amistad cívica. 
Finalmente, es necesario considerar que Rahner ofrece algunas herramientas claves para abordar una teología del poder que prevenga la corrupción, entre otros males sociales e intraeclesial. Sin embargo, la mayor posibilidad de esta teología es que necesita encausarse mediante una educación para el buen ejercicio del poder, cimentada en la responsabilidad personal y social de cada ser humano. Aquello permitirá el redescubrimiento de la trascendentalidad de las acciones que desarrolla cada persona.

Por este motivo es importante que los líderes de la sociedad y los eclesiales, se puedan formar en este aspecto y así trabajar habilidades del buen ejercicio del poder. Este hecho podría evitar algunas problemáticas de las cuales el mundo entero ha sido víctima, cuyas heridas necesitarán años para cicatrizar, como lo ha demostrado, en el caso chileno, la violación a los derechos humanos en la dictadura cívico-militar; los actuales abusos de poder en instituciones de distinta índole; la violencia de género, y los abusos sexuales, de poder y de conciencia hacia niños y jóvenes, tanto en las propias familias como a través de instituciones del estado, privadas y eclesiales.

Una formación seria, con respecto al poder, podría marcar la diferencia entre una sociedad corrupta y una sociedad fraterna.

\section{REFERENCIAS}

-Abarca, N. (2004). Inteligencia emocional en el liderazgo. Santiago de Chile: El Mercurio Aguilar.

-Aros, J. (2011a). Iluminación teológica del encuentro con Cristo desde el concepto de autocomunicación de Dios en el Curso fundamental sobre la fe de Karl Rahner. Medellin, 37(147), 343-370.

-Aros, J. (2011b). La autocomunicación absoluta de Dios en sí mismo según Karl Rahner. Veritas, (25), 133-151.

-Aros, J. (2016). Una lectura de la misión de la universidad católica desde el prisma de la trascendencia del hombre en el pensamiento de Karl Rahner. Franciscanum, 58(166), 179-215.

-Bauman, Z. (2007). Vida de consumo. México: F.C.E.

-Benbenaste, N., Delfino, G. \& Vitale, N. (2006). La contribución de la psicología al concepto del poder. Universitas Psychologica, 5(2), 351-360.

-Benedicto XVI (2009). Caritas in veritate. Santiaago de Chile: San Pablo.

-Castelao (2013). Antropología Teológica. En A. Cordovilla (ed.), La lógica de la fe. Manual de Teología Dogmática (pp.171-274). Madrid: Universidad Pontificia Comillas.

-CELAM, (2007). IV Conferencia General del Episcopado latinoamericano, Documento conclusivo de Aparecida. Bogotá: Celam.

-Concilio Vaticano II (2000a). Lumeng entium. Madrid: BAC.

-Concilio Vaticano II (2000b). Gaudium et Spes. Madrid: BAC. 
-Consejo asesor presidencial contra los conflictos de interés, el tráfico de influencias y la corrupción (2015). Informe final. Disponible en http://www.minsegpres.gob.cl/wp-content/uploads/2017/04/Informe-del-Consejo-Asesor-Presidencial-Contra-los-Conflictos-de-Intereses-el-trafico-de-Influencias-la-Corrupcion.pdf

-Correa, M. (2017). Ética, profesión y desarrollo. En S. Brito \& L. Basualto, La construcción de la paz en contextos universitarios. Una tarea compartida (pp. 75-86). Santiago de Chile: UCSH.

-Covey, S. (2009). El lider interior. Cómo transmitir e inspirar los valores que conducen a la grandeza. Buenos Aires: Paidós.

-De la Pienda, J. A. (1982). Antropología trascendental de Karl Rahner. Una teoría del conocimiento, de la evolución y de la historia. Oviedo: Universidad de Oviedo.

-Domingo Moratalla, A. (2014) Democracia y caridad. Horizontes éticos para la donación y la responsabilidad. Maliaño, Cantabria: Sal Terrae.

-Fernández, M. (2018). Engels y el caso SQM: "Echa por la borda el esfuerzo de varios dirigentes empresariales para recuperar la confianza ciudadana”. Disponible en https://www.latercera.com/la-tercera-pm/noticia/engel-echala-borda-esfuerzo-varios-dirigentes-empresariales-recuperar-la-confianzaciudadana/194785/

-Fischman, D. (2014). Motivación 360. Cómo incrementarla en la vida y en la empresa. Santiago de Chile: El Mercurio Aguilar.

-Flecha, J. R. (2007). Moral social. La vida en comunidad. Salamanca: Sígueme.

-Flores, P. (2014). El lider que escucha desde la abundancia. Santiago de Chile: RIL.

-Francisco (2013). Evangelii Gaudium. Santiago de Chile: San Pablo.

-Francisco (2018). Conferencia de prensa del Santo Padre durante el vuelo de regreso a Roma (domingo, 21 de enero). Disponible en http://w2.vatican.va/content/francesco/es/speeches/2018/january/documents/papa-francesco_20180121_peru-voloritorno.html

-Galeano, A. (2016). Un nuevo paradigma de la teología católica. Las dimensiones histótico-cósmicas del Misterio cristiano. Cuestiones teológicas, 43(100), 359-384.

-Galindo, A. (1996). Moral socioeconómica. Madrid: BAC.

-Garcés, M. (2012). El despertar de la sociedad. Los movimientos sociales en América Latina y Chile. Santiago de Chile: LOM.

-Goleman, D. (2013). Liderazgo. El poder de la inteligencia emocional. Barcelona: Ediciones BSA.

-Goleman, D., Boyatzis, R. \& McKee, A. (2010). El líder resonante crea más. Buenos Aires: Debolsillo.

-Hernández, J. (2017). Crónica actual sobre transparencia y corrupción. Revista Internacional Transparencia e integridad, (3), 1-5.

-Hobbes, T. (2017). O la materia, forma y poder de una república eclesiástica y civil. México: F.C.E.

-Höffe, O. (2007). Ciudadano económico, ciudadano el Estado, ciudadano del mundo. Ética política en Höffe, la era de la globalización. Buenos Aires: Katz.

-Höffe, O. (2008). El proyecto politico de la modernidad. Buenos Aires: F.C.E. 
-Holloway, J. (2002). Cambiar el mundo sin tomar el poder. El significado de la revolución boy. Puebla: El viejo topo.

-Hurtado, A. (2004). Moral social. Santiago de Chile: UC

-Hurtado, A. (2005). Hay una manera cristiana de trabajar. En S. Fernández (ed.), La búsqueda de Dios: conferencias, artículos y discursos del Padre Alberto Hurtado, S.J. Santiago de Chile: PUC.

-Latouche \& Harpagès (2011). La hora del decrecimiento. Barcelona: Octaedro.

-Latouche, S. (2012). Salir de la sociedad de consumo. Voces y vías del decrecimiento. Barcelona: Octaedro.

-Latouche, S. (2014). Limite. Buenos Aires: AH.

-Lukes, S. (2007). El poder. Un enfoque radical. Madrid, España: Siglo XXI.

-Martínez, J. (2011). Moral socialy espiritualidad. Una co(i)inspiración necesaria. Santender: Sal Terrae.

-Martínez, O. (2009). Corrupción y poder. Revista Comunicación, (26), 99-109.

-Maxwell, J. (2004). El ABC del liderazgo. Buenos Aires: V\&R editoras.

-Meis, A. (1993). La paradoja del origen: hacia una consolidación teológica del pecado original. Teología y Vida, 34, 261-280.

-Orellana, P. (2007). Chile, un caso de corrupción oculta. Revista de sociología, (21), 257-272.

-Pasquino, G. (2015). Los retos de la democracia en América latina. Temas y debates, (29), 105-112.

-Pinker, S. (2012). Los ángeles que llevamos dentro. El declive de la violencia y sus implicaciones. Barcelona: Paidós.

-Pontificio Consejo Justicia y Paz (2006). La lucha contra la corrupción. Disponible en http://www.vatican.va/roman_curia/pontifical_councils/justpeace/documents/rc_pc_justpeace_doc_20060921_lotta-corruzione_sp.html

-Pontificio Consejo Justicia y Paz (2014). Compendio de la doctrina social de la Iglesia. Madrid: BAC.

-Putz, G. (1993). Poder. En H. Rotter \& G. Virt, Nuevo diccionario de moral cristiana (pp. 466-469). Barcelona: Herder.

-Rahner, K. (1972). Dios trino como principio y fundamento trascendente de la historia de salvación. En J. Feiner \& M. Löhrer (ed.), Mysterium Salutis (v.II, pp. 316-317). Madrid: Cristiandad.

-Rahner, K. (1976). Curso fundamental sobre la fe. Barcelona: Herder.

-Rahner, K. (2002). Teología del poder. En K. Rahner, Escritos de teología IV (pp. 449-469). Madrid: Cristiandad.

-Sánchez, J. (2005). Historia de la Iglesia II: Edad media. Madrid: BAC.

-Sandoval, C. (2016). De jefe a lider. Hacer que las cosas pasen. Santiago de Chile: Aguilar.

-Sharma, R. (2012). El lider que no tenía cargo. Una fábula moderna sobre el liderazgo en la empresa y en la vida. Barcelona: Debolsillo.

Sumario: Introducción; 1. Poder como don de Dios; 2. El poder como tarea de humanización; 3. El poder como posibilidad de construir el Reino; Conclusiones; Referencias. 